\title{
Review Article \\ HIV-Related Immune Activation and Inflammation: Current Understanding and Strategies
}

\author{
Tingxia Lv $\mathbb{D}^{1,2}$ Wei Cao, ${ }^{1}$ and Taisheng $\mathrm{Li} \mathbb{D}^{1,3,4}$ \\ ${ }^{1}$ Department of Infectious Diseases, Peking Union Medical College Hospital, Chinese Academy of Medical Sciences \& Peking Union \\ Medical College, Beijing 100730, China \\ ${ }^{2}$ Department of Infectious Diseases, Beijing Friendship Hospital, Capital Medical University, Beijing, China \\ ${ }^{3}$ Department of Basic Medical Sciences, School of Medicine, Tsinghua University, Beijing 100084, China \\ ${ }^{4}$ Tsinghua-Peking Center for Life Sciences, Beijing 100084, China \\ Correspondence should be addressed to Taisheng Li; litsh@263.net
}

Received 19 July 2021; Accepted 20 September 2021; Published 29 September 2021

Academic Editor: Xuan Huang

Copyright (c) 2021 Tingxia Lv et al. This is an open access article distributed under the Creative Commons Attribution License, which permits unrestricted use, distribution, and reproduction in any medium, provided the original work is properly cited.

\begin{abstract}
Although antiretroviral therapy effectively controls human immunodeficiency virus (HIV) replication, a residual chronic immune activation/inflammation persists throughout the disease. This aberrant immune activation and inflammation are considered an accelerator of non-AIDS-related events and one of the driving forces of $\mathrm{CD}^{+} \mathrm{T}$ cell depletion. Unfortunately, HIV-associated immune activation is driven by various factors, while the mechanism of excessive inflammation has not been formally clarified. To date, several clinical interventions or treatment candidates undergoing clinical trials have been proposed to combat this systemic immune activation/inflammation. However, these strategies revealed limited results, or their nonspecific antiinflammatory properties are similar to previous interventions. Here, we reviewed recent learnings of immune activation and persisting inflammation associated with HIV infection, as well as the current directions to overcome it. Of note, a more profound understanding of the specific mechanisms for aberrant inflammation is still imperative for identifying an effective clinical intervention strategy.
\end{abstract}

\section{Introduction}

With the development of well-tolerated and highly effective antiretroviral therapy (ART), HIV/AIDS has changed from a fatal disease into a chronic and controllable condition [1]. As a result, the life expectancy of HIV-infected patients with a high $\mathrm{CD} 4^{+} \mathrm{T}$ cell count and an undetectable viral after ART is gradually approaching that of the uninfected population [2]. However, abnormal immune activation and inflammation are accompanied by the whole infection process, and antiviral therapy alone is challenging to solve these clinical problems. For example, people living with HIV (PLWH) after successful ART still showed a higher level of immune activation, characterized by elevated biomarkers such as IL-6, D-dimer, C-reactive protein (CRP), and sCD14 [3, 4]. Chronic immune system activation is a hallmark of HIV infection and better predicts disease outcome than plasma viral load [5]. However, clinical data suggested that only up to $30 \%$ of patients after ART present a modest rise of $\mathrm{CD} 4^{+} \mathrm{T}$ cell levels, far from effective immune reconstitution. Moreover, levels of inflammation are associated with disease progression in PLWH [6-8], which predicts an accelerated and accentuated onset of serious non-AIDS events (SNAEs), such as neurocognitive disorders, coronary artery disease, chronic liver/kidney dysfunction, metabolic syndrome, osteoporosis, and non-HIV-associated cancers $[8,9]$. As a result, patients remain susceptible to opportunistic infections and are more prone to disease progression and poor outcomes in this setting.

Admittedly, the persistence of the HIV-1 reservoir after ART is an important reason for HIV-related immune activation and inflammation [10,11]. However, HIV-related immune activation and inflammation are a systematic and long-term process, and many other factors and mechanisms are also involved. Given its complexity and burden for patients, treatment for abnormal immune activation and inflammation has 
gradually become indispensable, and clinical trials using antiinflammatory properties are underway to eliminate this phenomenon. This review will systematically elucidate the current mechanisms and therapeutic strategies/drugs for HIV-related immune activation and inflammation.

\section{Driving Factors for HIV-Related Immune Activation}

After the antigenic stimulation of the HIV, T cell is activated and induces the innate and adaptive immune response. However, the immune activation continues even after the HIV-1 viral load decreased to an undetectable level. The underlying mechanisms of persistent immune activation are complex, and various factors have been proposed to date.

2.1. The Persistence of HIV Viral Reservoirs. Continuous production of viral particles by reservoir cells in ART patients remains an important source of immune activation [12]. Admittedly, viral load and inflammation were decreased and $\mathrm{CD}^{+} \mathrm{T}$ cell elevated after ART [13]. However, after combined antiretroviral therapy (cART), a small amount of HIV in the reservoirs cannot be eliminated. Consequently, its expression products activate lymphocytes and macrophages to cause immune activation. For example, HIV envelope glycoprotein 120 (gp120) induces IL-1 $\beta$ release from macrophages through binding to the chemokine receptor CCR5 and coupling to G(i)alpha protein [14]. HIV-1 structural proteins, p17, p24, and gp41, act as viral pathogenassociated molecular pattern (PAMP) signaling through TLR2 and its heterodimers leading to significantly increased immune activation via the $\mathrm{NF} \kappa \mathrm{B}$ signaling pathway [15]. Likewise, HIV-1 ssRNA interacts with the pattern recognition receptors TLR-7 and TLR-9 in plasmacytoid dendritic cells and induces the production of IFN- $\alpha$ and may therefore contribute to chronic immune activation [16]. Thus, HIV-1 persistence in individuals is at an increased risk for developing non-AIDS-related comorbidities $[17,18]$. It is reported that pretreatment $\mathrm{CD}^{+} \mathrm{T}$ cell activation, nadir $\mathrm{CD}^{+} \mathrm{T}$ count, and $\mathrm{CD} 4: \mathrm{CD} 8$ ratio might predict reservoir size [19]. Studies also have shown that administration of integrase inhibitors could partially reduce the reservoirs, decrease the number of infected memory $\mathrm{CD}^{+} \mathrm{T}$ cells, and significantly decrease immune activation levels such as $\mathrm{CD} 8^{+} \mathrm{CD}^{+} \mathrm{T}$ cells [20-22]. Based on the current understanding of HIV, therapy targeting HIV repositories is undoubtedly one of the critical strategies.

2.2. Intestinal Microbial Translocation. The disturbance in gut microbiota has been widely reported in HIV-infected subjects compared with healthy controls [23, 24]. Generally, $\mathrm{HIV}$ destroys the $\mathrm{CCR} 5^{+} \mathrm{CD} 4^{+} \mathrm{T}$ cells, which are abundantly present in the gut-associated lymphoid tissues, leading to the destruction of the intestinal mucosal barrier. Then, many intestinal microbial and their metabolites entered the blood circulation, inducing immune activation and hyperinflammatory response $[25,26]$. Circulating lipopolysaccharide (LPS), an indicator of microbial translocation, was significantly increased in chronically HIV-infected individuals and simian immunodeficiency virus- (SIV-) infected rhesus macaques $[5,27]$. The microbial translocation is also associated with the proportion of $\mathrm{CD}^{+} \mathrm{T}$ cells overexpressing CD38, IFN concentration in the blood [26], and sustained failure during $\mathrm{CD}^{+} \mathrm{T}$ cell reconstitution in treated patients [28]. On the other hand, the high inflammatory state of intestinal mucosa and apoptosis of intestinal epithelial cells further promoted intestinal microbial translocation [29]. Therefore, dysregulation of intestinal microbial and microbial translocation is significantly correlated with immune and inflammatory activation [30].

2.3. Depletion of Regulatory $T$ (Treg) Cells. The distribution of Treg cells, the potent natural regulator, changed during chronic HIV infection and was accompanied by a shift of $\mathrm{CD} 4{ }^{+} \mathrm{CD} 25^{+}$Treg from the peripheral blood to peripheral lymph nodes and mucosal lymphoid tissues [31-33]. Treg cells can inhibit $\mathrm{T}$ cell activation and proliferation through contact-dependent mechanisms, but Treg cell itself is vulnerable to HIV infection, leading to a significant functional deficit $[34,35]$. Treg cells were also reported to control immune activation during HIV-1 infection through impairing IL-2 production [36]. Even in HIV elite controllers, the decreased Treg cells are strongly associated with immune activation and can increase the incidence of atherosclerosis and other related inflammatory diseases [37, 38]. In other words, growing Treg cells may reduce HIV-associated immune activation, which is the basis of current clinical trials using statins to suppress immune activation [39].

2.4. Coinfection with Other Viruses. Compared to HIVmonoinfected individuals, patients with other virus infections have elevated soluble inflammatory biomarkers and surface markers of $\mathrm{T}$ cell activation [40-43]. HIV infection also leads to the lower immune function of the body and often causes the reactivation of some viruses that have been lurking in the body for a long time, such as cytomegalovirus (CMV) and human herpesvirus (HSV). Margolick et al. showed that in well-controlled HIV-infected patients, the body's specific T cell response to CMV would affect chronic immune activation [44]. Active HSV infection, regardless of symptoms, involves the recruitment of activated $\mathrm{CD} 4^{+} \mathrm{T}$ cells to the genital area and can lead to breaks in the mucosal layer through which HIV can enter $[45,46]$. HIV-1 infection also impairs HSV-specific $\mathrm{CD}^{+}$and $\mathrm{CD}^{+} \mathrm{T}$ cell response by reducing Th1 cytokines and CCR5 ligand secretion [47], while HSV-2 infection significantly increases the susceptibility of the host to acquire HIV and promotes the shedding of the latter during the coinfection [48]. In addition, in patients coinfected with HIV and HCV, the inflammatory response, platelet activation, and oxidative stress are more intense, indicating its enhanced immune activation $[49,50]$.

\section{Pathogenesis of HIV-Related Inflammation}

3.1. Toll-Like Receptors (TLRs) and Nuclear Factor-Kappa B (NF- $\kappa B$ ) Activation. Toll-like receptors (TLR1-10) are pattern recognition receptors (PRRs) expressed on the surface or inside various immune cells, which could recognize 
multiple PAMPs such as LPS, peptidoglycan, virus, and nucleic acid [51]. HIV single-stranded RNA (ssRNA) and double-stranded RNA (dsRNA) are formed during their life cycle and can be recognized by intracellular TLRs. For example, TLR7 recognizes the HIV ssRNA, leading to the destruction of $\mathrm{T}$ cells and the release of inflammatory cytokines [52]. Inflammatory activation caused by TLR3 recognition of HIV dsRNA is linked with HIV-associated blood-brain barrier disorders and neurological dysfunction [53]. HIV infection can also lead to the expression changes of TLRs. For example, TLR3 and TLR4 are not expressed in T cells of healthy people, but their expression is significantly increased after HIV infection [54]. HIV-1 ssRNA stimulation of neutrophils leads to enhanced expression of TLR7/8, RIG-I, and MDA5, decreased expression of TLR2, induction of cytokines (TNF- $\alpha$ and IL-6), and production of ROS [55]. In addition, after HIV infection, the gp120 activates $\operatorname{IKK} \beta$, which subsequently leads to endogenous I $\kappa \mathrm{B} \alpha$ phosphorylation, nuclear translocation of NF- $\kappa \mathrm{B}$, and then overexpression of IL-6 and IL-8 [56]. HIV-associated neurocognitive disorders (HAND), which exist in approximately $50 \%$ of infected individuals even after a highly active antiretroviral therapy, correlate with the activation of NF- $\kappa B$ [57]. For example, in central nervous system lesions, HIV transactivator of transcription (Tat) protein induces the expression of proinflammatory genes in astrocytes, which ultimately activates NF- $\kappa \mathrm{B}$ and upregulates the expressions of MCP-1, IL-8, CXCL10, etc. [58]. Additionally, decrement in excitatory amino acid transporter 2 (EAAT-2) in astrocyte plasma membranes leads to elevated levels of extracellular glutamate, while this increased EAAT-2 inhibition via the NF- $\kappa$ B signaling pathway during HAND [59].

3.2. Interferon and Interferon-Stimulated Genes. HIV triggers the induction of type I IFN (IFN- $\alpha / \beta)$, providing a crucial mechanism of antiviral defense and inflammation response $[60,61]$. Interferon regulatory factors also participate in the induction of type I interferon, and interferonstimulated genes (ISG) produce many subsequent effects [62]. It was reported that IFN- $\alpha / \beta$ binding to cell surface receptors induces the expression of ISG-15 by activating the downstream JAK-STAT pathway $[53,63]$. The expression of ISG-15 was positively correlated with plasma viral load and $\mathrm{CD}^{+}{ }^{+} \mathrm{T}$ cell count in HIV-1 chronically infected patients [64]. Moreover, ISG-15 increases the expression of IP-10, a critical inflammatory factor in HIV-induced immune dysfunction and disease progression, by activating $\mathrm{NF}-\kappa \mathrm{B}$, suggesting the crosstalk between the NF- $\kappa \mathrm{B}$ and interferon signaling [65]. In addition, the expression of IP10 is also negatively regulated by miR-21, and the increased expression of ISG-15 can also reduce the inhibitory effect of miR-21 on IP-10 [66].

3.3. Cysteinyl Aspartate-Specific Protease- (Caspase-) Induced Cell Apoptosis and Pyroptosis. Caspase family participates in apoptosis/pyroptosis under various stimulation, such as cytokines and DNA damage, of which caspase-3/8/9 is the main effector of cell apoptosis and caspase-1 mediated the pyroptosis [67]. HIV-infected cells exhibited increased pro- grammed cell death, such as apoptosis, pyroptosis, and ferroptosis than uninfected cells [68]. The decrease of $\mathrm{CD}^{+}$ $\mathrm{T}$ cells can be simultaneously mediated by apoptosis and pyroptosis, while the immune activation is more closely related to pyroptosis during HIV infection $[69,70]$. It is reported that the main pattern of $\mathrm{CD}^{+} \mathrm{T}$ cell death caused by HIV is caspase-1-mediated pyroptosis (about $95 \%$ ), while the proportion of cell apoptosis is less than 5\% [70]. In HIVinfected patients without ART, caspase-1/3 expression in $\mathrm{CD}^{+} \mathrm{T}$ cells and caspase- 3 expression in $\mathrm{CD} 8^{+} \mathrm{T}$ cells were significantly increased [71]. Meanwhile, there was a positive correlation between HLA-DR ${ }^{+} \mathrm{CD} 38^{+} \mathrm{CD} 8^{+} \mathrm{T}$ cells and $\mathrm{CD} 4^{+} \mathrm{T}$ cells with high expression of caspase-1 [71]. In addition, caspase-1-mediated cell apoptosis plays a vital role in the occurrence and development of immune reconstitution inflammatory syndrome (IRIS), as evidenced by the increased serum cytokine levels and caspase-1/5 in HIVassociated tuberculosis infection patients with IRIS [72]. Besides cell death, caspases are also centrally involved in inflammation responses, among which the secretion of IL$1 \beta$ and IL-18 plays a key role [73]. After HIV infection, bystander $\mathrm{CD}^{+} \mathrm{T}$ cells produce HIV-1 DNA, which is recognized by the host DNA receptor interferon- $\boldsymbol{\gamma}$-inducible protein 16 (IFI16) and then binds to apoptosis-associated speckle-like protein (ASC) and procaspase-1 to form a functional inflammasome [74]. Then, the inflammasome mediated the cleavage and mature of pre-IL-1 $\beta$ and pre-IL-18. Meanwhile, the activated caspase- 1 also leads to increased cell permeability, edema/rupture, and the release of other damage-related molecular patterns (DAMP) such as HMGB1, IL-33, and inflammatory cytokines [67, 70, 71]. It is worth mentioning that the transmission of HIV between cells promotes pyroptosis, while free virus particles could not induce pyroptosis of $\mathrm{CD}^{+} \mathrm{T}$ cells [75].

\section{Strategies to Reduce HIV-1 Related Immune Activation and Inflammation}

Currently, the strategies aimed at coping with HIV-1-related immune activation and inflammation are still challenging due to the complexity of immune activation, the differences of the PLWH population, and uneven inclusion criteria. However, some drugs are emerging in the experimental stage though there is still a long way to go before eradicating immune activation.

\subsection{Immunosuppressive Drugs}

4.1.1. Prednisolone. In 2012, Kasang et al. reported that prednisolone has beneficial effects on immunological correlates of HIV disease progression in untreated HIV-infected patients $\left(\mathrm{CD} 38^{+} \mathrm{CD} 8^{+} \%, \mathrm{CD} 38^{+} \mathrm{CD} 4^{+} \%, \mathrm{sCD} 14\right.$, and LPSbinding protein (LBP)), but no additional beneficial effects in patients treated with ART [76]. Consistent with this viewpoint, Wallis et al. reported that no effect on markers of cell activation or apoptosis after eight weeks of prednisone $(40 \mathrm{mg} / \mathrm{d})$ treatment as an adjunct to ART in $24 \mathrm{HIV}$ infected subjects with $>200 \mathrm{CD} 4^{+} \mathrm{T}$ cells $/ \mu \mathrm{L}$ [77]. Similarly, a randomized clinical trial of prednisolone $(5 \mathrm{mg}$ /day, two 
years) applied in ART naïve patients showed a significant decrease in immune activation (sCD14, suPAR, and CD38/HLA-DR/CD8 ${ }^{+}$) and an increase in $\mathrm{CD} 4^{+} \mathrm{T}$ counts, while no significant effect on the primary endpoint of HIV disease progression to AIDS although viral load increased quickly than placebo [78]. Therefore, these facts might illuminate that prednisolone is more possibly associated with a stabilization of $\mathrm{CD}^{+} \mathrm{T}$ cell count $[79,80]$, which predicted the promising application of prednisolone in abnormal immune activation after clearance of HIV.

4.1.2. Chloroquine/Hydroxychloroquine (CQ/HCQ). Agents with immunosuppressive properties were first tried in PLWH in 1998, which could both break the vicious cycle that leads to the slow attrition of the lymphocyte pools [81]. Both CQ and HCQ have been widely used in treating autoimmune conditions, such as lupus and arthritis, and they could also suppress the HIV-1 replication in patients [82]. In 2010, Murray et al. reported the combination usage of CQ with ART in PLWH and indicated a reduced activation and proliferation of memory $\mathrm{CD} 8^{+} \mathrm{T}$ cells (proportions of HLA-DR, CD38, and Ki67 expression), as well as plasma LPS levels [83]. Piconi and colleagues also reported that HCQ (400 mg daily) reduced the level of activated $\mathrm{CD} 4^{+}(-$ $\left.\mathrm{CD} 4^{+} / \mathrm{Ki} 67^{+}\right), \mathrm{CD} 14^{+}\left(\mathrm{CD} 14^{+} / \mathrm{CD} 9^{+}\right) \mathrm{T}$ cells, and IL$6 / \mathrm{TNF}-\alpha$, but increased the proportion of Tregs [84]. However, a placebo-controlled trial in the United Kingdom in 2012 showed that among HIV-infected patients not taking ART, 48 weeks of HCQ monotherapy $(400 \mathrm{mg} / \mathrm{d})$ did not reduce $\mathrm{CD}^{+} \mathrm{T}$ cell activation and IL-6/D-dimer level but did result in a more significant decline in $\mathrm{CD}^{+} \mathrm{T}$ cell count and increased viral replication [85]. Furthermore, Routy et al. conducted an open-labeled single-arm study and found no substantial changes in the levels of immune activation or inflammation markers (HLA-DR, CD38, and IL-6) after 24 weeks of ART+CQ (250 mg/d) [86]. Therefore, the role of CQ/HCQ in HIV-induced immune activation/inflammation is limited, especially in the presence of HIV. Of note, the conflicting results among different studies might be partially derived from the insufficient dosage of $\mathrm{CQ} / \mathrm{HCQ}$.

4.1.3. Cyclosporin A (CsA). Clinical trials suggested that CsA treatment was associated with modest but transient increases in the $\mathrm{CD} 4^{+} \mathrm{T}$ count and delayed progression to AIDS [87-89]. Cyclosporin treatment also significantly decreased the production of various cytokines (IL-2, TNF- $\alpha$, and IFN- $\gamma$ ) in vitro [90]. Rizzardi et al. enrolled nine patients with primary HIV infection to receive CsA $(0.3-0.6 \mathrm{mg} / \mathrm{kg})$ in conjunction with ART for eight weeks, after which CsA was discontinued and ART continued for another 58 weeks. Results showed that patients with CsA treatment experienced a significant rise in $\mathrm{CD} 4^{+} \mathrm{T}$ count compared to the HAART-only control. Additionally, the proportion of IFN- $\gamma$-secreting CD4+CCR7-T cells was significantly higher in the CsA group during treatment [91]. However, it is essential to underscore that CsA must be used with ART; otherwise, patients' conditions might deteriorate quickly $[89,92,93]$.
4.1.4. Rapamycin (RAPA). As known to date, RAPA is a macrocyclic lactone antibiotic with immunosuppressive properties and is currently used for prophylaxis of rejection in patients following organ transplantation. RAPA exerts its immunosuppressive function by inhibiting the mammalian target of rapamycin (mTOR) and further prevents cytokine-mediated $\mathrm{T}$ cell proliferation $[94,95]$. In addition, RAPA can repress HIV-1 replication and reduce the release of IL- 8 and MIP- $1 \alpha$ in PBMC induced by $\alpha \mathrm{CD} 3 / \alpha \mathrm{CD} 28$ [90, 96]. Coadministration of RAPA with CsA achieved a more obvious suppressive effect for HIV-1 reactivation in vitro and inhibited the production of cytokines such as IL-2, MCP-1, MIP- $1 \alpha$, IL- $1 \beta$, IFN- $\gamma$, TNF- $\alpha$, and IL-6 [90]. The first clinical trial of RAPA was conducted in six HIVinfected individuals $\left(\mathrm{CD}^{+} \mathrm{T}\right.$ cell count $>100 / \mu \mathrm{L}$ and $\mathrm{VL}<$ 50 copies $/ \mathrm{mL}$ ) who received liver transplantation, and results showed that patients who switched to RAPA monotherapy present improved control of HIV but no benefit in maintaining a higher $\mathrm{CD} 4^{+} \mathrm{T}$ cell count compared to those treated with calcineurin inhibitors [97].

4.1.5. Tripterygium wilfordii Hook $F$ (TwHF). As a traditional Chinese medication, TwHF has been widely used to treat different autoimmune diseases, including rheumatoid arthritis and active Crohn's disease $[98,99]$. Among the significant bioactive component extracted from TwHF, triptolide has been demonstrated to reduce LPS-induced inflammation [100-103]. Li et al. creatively combined TwHF $(10 \mathrm{mg}$, three times/d) with ART in 18 immune nonresponder HIV patients. After one year of treatment by TwHF extract, $\mathrm{CD} 4^{+} \mathrm{T}$ cell count markedly increased, and the percentage of $\mathrm{CD} 38^{+} \mathrm{HLA}-\mathrm{DR}^{+}$expressed on $\mathrm{CD} 8^{+} \mathrm{T}$ and $\mathrm{CD} 4^{+}$ $\mathrm{T}$ cells decreased significantly during the 12 -month treatment period [104]. Given these promising results, randomized placebo-controlled studies that enrolled more patients are warranted to evaluate the effects of TwHF extract on HIV patients.

4.2. Stains. Statins, including atorvastatin, fluvastatin, lovastatin, pitavastatin, pravastatin, rosuvastatin, and simvastatin, were generally used to decrease cholesterol. In recent years, statins have been tried for controlling HIVassociated inflammation but yielded mixed results. Ganesan et al. conducted a study in which 24 HIV-1-infected and ART naïve adults were enrolled to receive either atorvastatin $80 \mathrm{mg}$ daily or placebo for eight weeks (phase A), followed by a washout phase of 4-6 weeks and a subsequent switch to complete additional 8 weeks (phase B) in the opposite assignment. The results showed that atorvastatin reduced the proportions of circulating $\mathrm{CD} 4^{+} \mathrm{HLA}-\mathrm{DR}^{+}(-2.5 \%)$, $\mathrm{CD}^{+}{ }^{+} \mathrm{HLA}-\mathrm{DR}^{+} \quad(-5 \%), \quad \mathrm{CD} 8^{+} \mathrm{HLA}-\mathrm{DR}^{+} \mathrm{CD} 38^{+} \quad \mathrm{T}$ cells $(-3 \%)$ [105]. In contrast, in another study by Eckard et al., no statistically significant difference was observed in the percentage of hsCRP, IL-6, sTNFR-I/II, IP10, and D-dimer between rosuvastatin (10 $\mathrm{mg}$ daily for 24 weeks) and placebo at initial analysis [106]. However, the secondary analysis demonstrated that rosuvastatin reduced sCD14, Lp-PLA2, and IP-10 levels over 48 weeks, with a greater decrease in the proportion of activated $\left(\mathrm{CD} 38^{+} \mathrm{HLA}-\mathrm{DR}^{+}\right) \mathrm{T}$ cells 
between the arms $(-38.1 \%$ vs. $-17.8 \%$, or CD4+ cells and $-44.8 \%$ vs. $-27.4 \%$ for CD8+ cells) [107]. It is worth noting that the safety and drug-drug interactions regarding stains should be carefully considered. For example, atorvastatin appears to be relatively safe for long-term use at submaximal doses if monitored, while pravastatin, rosuvastatin, and pitavastatin appear to have the most benign safety profiles among statins when coadministered with ART and may not require dose adjustment [108].

\subsection{Treatment on Microbial Translocation}

4.3.1. Probiotics/Prebiotics. Given the crucial role of decreasing bacterial translocation and proinflammatory cytokine production in the maintenance of gut homeostasis, new therapies aimed at restoring the integrity of the epithelial and gut-associated lymphoid tissue (GALT) through oral prebiotics, probiotics, or synbiotics are promising for alleviating HIV-related disease progression. Disturbance in gut microbiota has been widely reported in HIV-infected subjects, and specific intestinal microbiota might benefit HIVinfected patients during ART by improving the microbiota composition and reducing mucosal and systemic inflammation $[109,110]$. Probiotics/prebiotics was partially reported to improve gastrointestinal immunity in SIV-infected macaques [111] and decrease microbial translocation and immune activation in ART-treated HIV-infected individuals $[109,112,113]$. However, the results were not always encouraging. Hummelen et al.'s study enrolled 32 women infected with HIV and given probiotic supplementation for 25 weeks; the results showed that changes in IFN- $\gamma$, IL-10, $\operatorname{IgG}$, and IgE did not differ from the placebo group, which is consistent with Villar-García et al.'s study [110, 114]. Additionally, based on the potential benefits of intestinal microorganisms, food additives such as vitamin [115], recombinant lactoferrin [116], and Mediterranean diet are also being explored in HIV patients [117]. In summary, the evidence for the efficacy of probiotics, prebiotics, and synbiotics in control inflammation as presented in current studies is insufficient, and further comprehensive studies are needed to reveal their exact effect.

4.4. Hypoglycemic Agents. Some hypoglycemic agents have been found to benefit microbiota composition, promote gut barrier integrity, and reduce inflammation in human and animal models of diabetes. For example, treatment with metformin in PLWH alleviated lipodystrophy syndrome, hyperlipidemia, and insulin sensitivity. Moreover, metformin prevented the progression of coronary artery calcification and calcified plaque volume in PLWH with metabolic syndrome [118]. In 6 nondiabetic PLWH, metformin decreased $\mathrm{CD}^{+}{ }^{+} \mathrm{T}$ cell expression of the marker of cell exhaustion programmed cell death-1 (PD-1) but not $\mathrm{T}$ cell activation markers CD38 and HLA-DR [119]. $\mathrm{CD}^{+} \mathrm{T}$ cell counts, $\mathrm{CD}^{+} / \mathrm{CD}^{+} \mathrm{T}$ cell ratios, and plasma markers of inflammation/gut damage underwent minor variations in the blood in response to metformin [120]. Furthermore, treatment of nondiabetic individuals with metformin controls inflammation by improving glucose metabolism and by regulating intracellular immunometabolic checkpoints [121]. Another hypoglycemic agent, sitagliptin, was previously reported to reduce inflammation and chronic immune cell activation in cART-treated HIV-infected adults with impaired glucose tolerance. After eight weeks of sitagliptin administration, plasma hsCRP and CXCL10 concentrations and adipose tissue MCP-1 abundance were significantly declined than placebo, while the $\mathrm{CD} 4^{+} / \mathrm{CD}^{+}$helper/suppressor ratio, D-dimer, and IL-6 concentrations were not significantly different [122]. Based on these preliminary but various results, large-scale and long-term studies are needed to determine whether hypoglycemic agents reduce cardiovascular risk and events in HIV-infected adults.

\subsection{Other Drugs}

4.5.1. Antiplatelet Agents. Increased platelet activity has been reported in ART-treated HIV infection, and in vitro studies showed that HIV-1 plasma could activate healthy platelets, which in turn activated monocytes, implicating a direct role for activated platelets in immune activation [123]. In addition, a higher thrombogenicity and inflammation/immune activation contribute to the increased cardiovascular disease risk in PLWH [124]. Therefore, antiplatelet agents were tried in ART-experienced patients. For example, one week of lowdose aspirin treatment for ART-treated HIV-1-infected subjects exhibited a decreased activation marker of T cell (CD38 and HLA-DR) and monocyte (sCD14), as well as enhanced leukocyte responses to Toll-like receptor stimulation [123]. Unfortunately, the latest result published in 2019 showed that aspirin administration $81 \mathrm{mg}$ daily in addition to ART did not benefit from decreasing inflammation, while another platelet inhibitor, clopidogrel, exhibited anti-inflammatory activity in PLWH [124]. Despite the mixed results to date, traditional interventions using antiplatelet agents to reduce CVD risk in HIV have been one choice, considering the overwhelming evidence that increased platelet activation is associated with an increased risk of cardiovascular events in PLWH.

4.5.2. Cyclooxygenase Type 2 (COX-2) Inhibitor. Cyclooxygenase is a critical-step enzyme in the inflammatory process, which results in the direct production of inflammatory mediators. Celecoxib, a COX-2 inhibitor, has been used for 12 weeks in PLWH without ART by Kvale's group in Norway and showed reduced $\mathrm{CD} 38^{+} \mathrm{CD} 8^{+} \mathrm{T} \%, \mathrm{PD}-1^{+} \mathrm{CD} 8^{+}$ T\%, IgA levels, and enhanced Treg number [125]. In 2017, this group published another study based on a novel COX2 inhibitor etoricoxib, which also obtains a sound effect for reducing activation of $\mathrm{CD} 8 \mathrm{~T}$ cells and improving Gagspecific $\mathrm{T}$ cell responses in ART naïve patients. However, in this study, etoricoxib does not modulate soluble markers of inflammation (sCD25, IP10, CD163, CD14, IL-6, and CRP), and in a surprise twist, no significant immunological effects were observed in ART-treated patients [126].

4.5.3. Medical Cannabis. Previous human studies suggested that cannabis, to some extent, reduced the related symptoms (anorexia, cachexia, and neuropathic pain) and morbidity/mortality in PLWH $[127,128]$. As for immune activation 


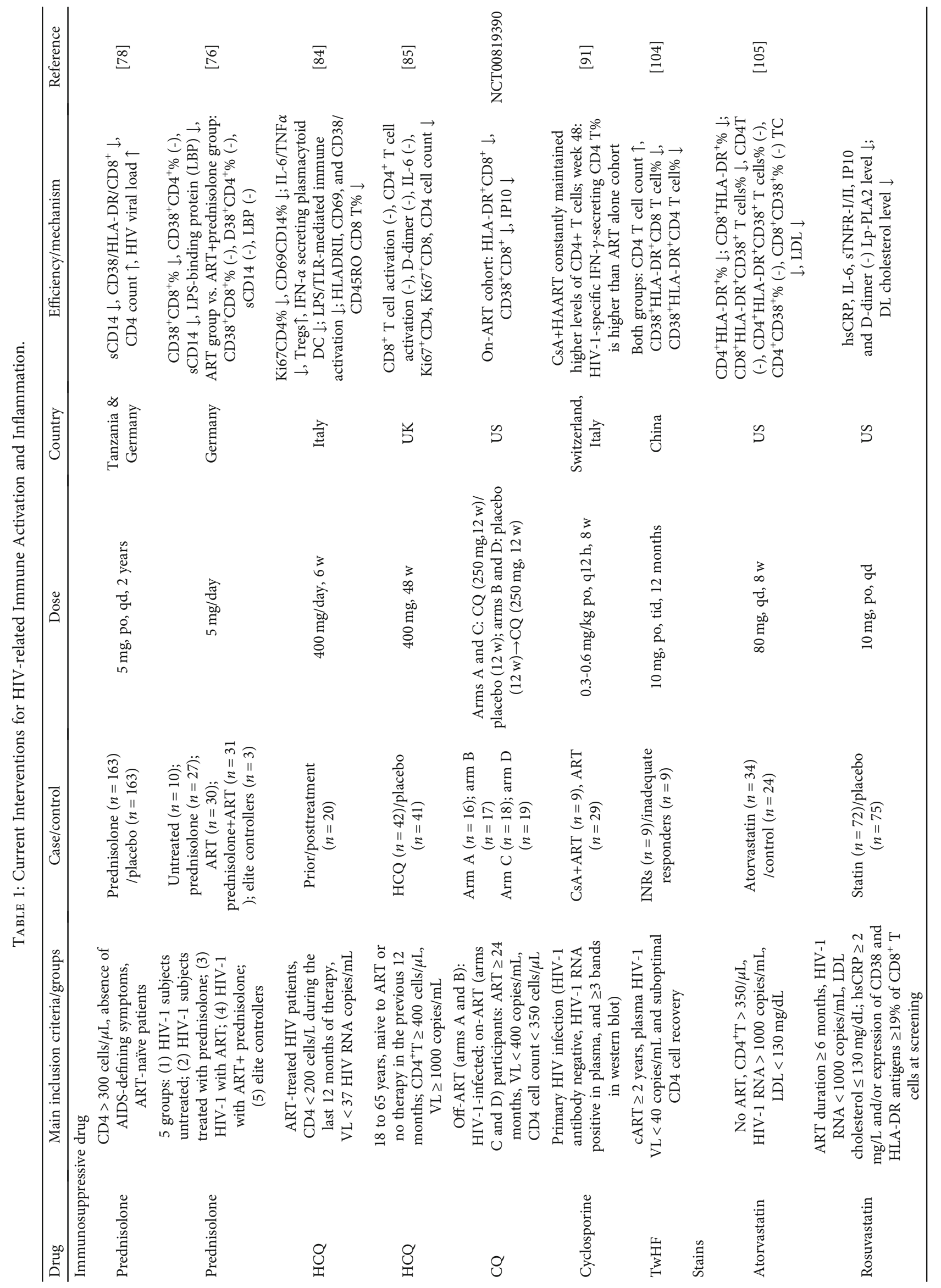




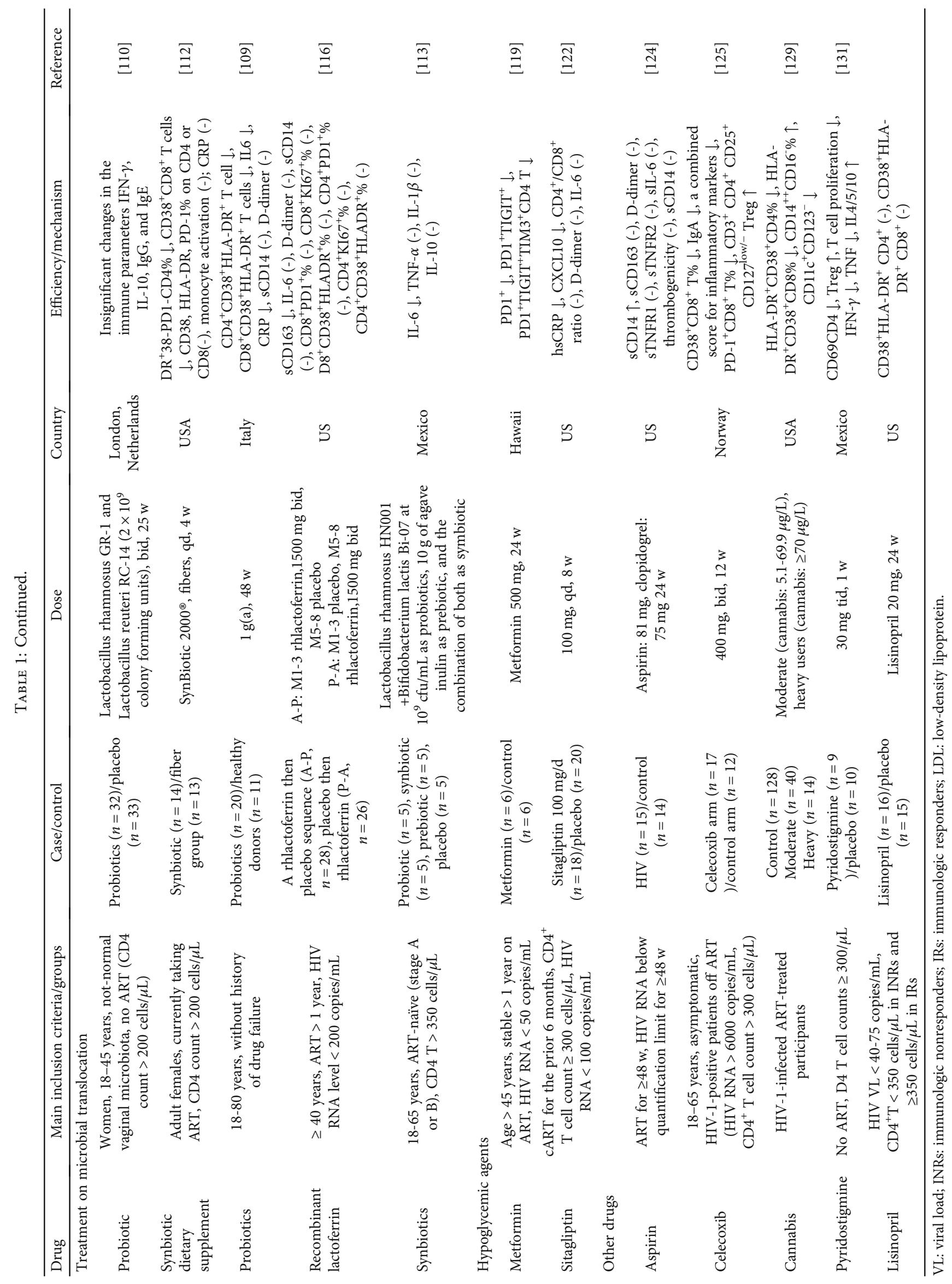


and inflammation in HIV patients, Manuzak et al. clarified that heavy cannabis users had decreased frequencies of HLA-DR ${ }^{+} \mathrm{CD} 38^{+} \mathrm{CD} 4^{+}$and $\mathrm{CD} 8^{+} \mathrm{T}$ cell, increased frequencies of classical monocyte subsets $\left(\mathrm{CD} 14^{++} \mathrm{CD} 16^{-}\right)$, and reduced frequencies of IL-23 and TNF- $\alpha$ producing antigen-presenting cells [129]. Moreover, recent cannabis use was associated with lower levels of inflammatory biomarkers, in both cerebrospinal fluid (CSF) and blood, suggesting its specific antineuroinflammatory effects [130]. Although there are promising benefits of cannabis for HIV/AIDS sufferers, the potential psychoactive side effects (impaired memory, euphoria, anxiety, and paranoia) and minor nonpsychoactive effects (sleepiness, tiredness, dry mouth, and red eyes) continue to be a barrier to its medical use. Also, the similar drug heroin was being tried in PLWH for treating immune activation and cardiovascular risk in HIV (NCT03976258), but no study results were posted to date.

Besides, following treatment of pyridostigmine, an ACh-esterase inhibitor, in 9 treatment-naive HIV-1 patients with $\mathrm{CD} 4^{+} \mathrm{T}$ cell count over 300 cells $/ \mu \mathrm{L}$, the fraction of $\mathrm{CD} 9^{+} \mathrm{CD} 4^{+} \mathrm{T}$ cells, IFN- $\gamma$, and TNF- $\alpha$ was significantly decreased, and Treg was dampened, while IL-4/6/10 were increased compared with placebo [131]. Dipyridamole was demonstrated to inhibit the replication of HIV-1 [132]; however, in virally suppressed persons with HIV on ART, it did not decrease the soluble markers of inflammation levels but modestly reduced the levels of $\mathrm{CD}^{+} \mathrm{T}$ cell activation [133]. Administration of mesalazine to subjects with poor $\mathrm{CD}^{+} \mathrm{T}$ cell gain on virologically suppressive cART did not affect markers of peripheral inflammation [134]. Moreover, leflunomide was proven to reduce the proliferation of activated $\mathrm{T}$ cells in vitro [135], but when applied in a small RCT in cART-naive patients, it showed no significant changes in activated $\mathrm{CD}^{+}$and $\mathrm{CD} 8^{+} \mathrm{T}$ cells [136]. Finally, the potential benefits for immune activation/inflammation among HIV-1-infected subjects of other drugs, such as isotretinoin (NCT01969058) and methotrexate (NCT01949116), require additional investigation [137].

\section{Conclusion and Perspective}

In conclusion, though many pathogeneses of HIV-related immune activation and inflammation, such as HIV-1 reservoir, coinfections, and various inflammatory signaling, have been clarified, the current understanding for this complex disease does not meet the need to develop specific therapeutic approaches. Moreover, non-AIDS-related events also accelerated the disease progression. Currently, though numerous approaches and strategies have been proposed for curing HIV (Table 1), no scalable solution has yet been reached. Therefore, on the one hand, a further understanding of the specific pathogenesis or their interaction causing aberrant HIV-associated immune activation/inflammation and effective intervention strategies is still imperative. On the other hand, drug intervention at the very early stage before the HIV reservoir is composed might be a promising strategy.

\section{Data Availability}

The data used to support the review are included within the article.

\section{Conflicts of Interest}

The authors declare that there is no conflict of interest regarding the publication of this paper.

\section{Acknowledgments}

This work was supported by the National Key Technologies R\&D Program for the 13th Five-year Plan (2017ZX10202101) and Chinese Academy of Medical Sciences (CAMS) Innovation Fund for Medical Sciences (CAMS-12M) (2017-12M-1-014).

\section{References}

[1] S. G. Deeks, S. R. Lewin, and D. V. Havlir, "The end of AIDS: HIV infection as a chronic disease," The Lancet, vol. 382, no. 9903, pp. 1525-1533, 2013.

[2] A. J. Rodger, R. Lodwick, M. Schechter et al., "Mortality in well controlled HIV in the continuous antiretroviral therapy arms of the SMART and ESPRIT trials compared with the general population," AIDS, vol. 27, no. 6, pp. 973-979, 2013.

[3] K. A. So-Armah, J. P. Tate, C. H. Chang et al., "Do biomarkers of inflammation, monocyte activation, and altered coagulation explain excess mortality between HIV infected and uninfected people?," Journal of Acquired Immune Deficiency Syndromes, vol. 72, no. 2, pp. 206-213, 2016.

[4] A. Kamat, V. Misra, E. Cassol et al., "A plasma biomarker signature of immune activation in HIV patients on antiretroviral therapy," PLoS One, vol. 7, no. 2, article e30881, 2012.

[5] J. M. Brenchley, D. A. Price, T. W. Schacker et al., "Microbial translocation is a cause of systemic immune activation in chronic HIV infection," Nature Medicine, vol. 12, no. 12, pp. 1365-1371, 2006.

[6] A. Ganesan, P. K. Chattopadhyay, T. M. Brodie et al., "Immunologic and virologic events in early HIV infection predict subsequent rate of progression," The Journal of Infectious Diseases, vol. 201, no. 2, pp. 272-284, 2010.

[7] A. J. Rodger, Z. Fox, J. D. Lundgren et al., "Activation and coagulation biomarkers are independent predictors of the development of opportunistic disease in patients with HIV infection," The Journal of Infectious Diseases, vol. 200, no. 6, pp. 973-983, 2009.

[8] P. W. Hunt, J. Brenchley, E. Sinclair et al., "Relationship between $\mathrm{T}$ cell activation and $\mathrm{CD} 4+\mathrm{T}$ cell count in HIVseropositive individuals with undetectable plasma HIV RNA levels in the absence of therapy," The Journal of Infectious Diseases, vol. 197, no. 1, pp. 126-133, 2008.

[9] C. T. Longenecker, C. Sullivan, and J. V. Baker, "Immune activation and cardiovascular disease in chronic HIV infection," Current Opinion in HIV and AIDS, vol. 11, no. 2, pp. 216-225, 2016.

[10] Z. Kruize and N. A. Kootstra, "The role of macrophages in HIV-1 persistence and pathogenesis," Frontiers in Microbiology, vol. 10, p. 2828, 2019. 
[11] M. Massanella, R. Fromentin, and N. Chomont, "Residual inflammation and viral reservoirs," Current Opinion in HIV and AIDS, vol. 11, no. 2, pp. 234-241, 2016.

[12] P. Corbeau and J. Reynes, "Immune reconstitution under antiretroviral therapy: the new challenge in HIV-1 infection," Blood, vol. 117, no. 21, pp. 5582-5590, 2011.

[13] C. Bourgeois, J. Gorwood, A. Olivo et al., "Contribution of adipose tissue to the chronic immune activation and inflammation associated with HIV infection and its treatment," Frontiers in Immunology, vol. 12, article 670566, 2021.

[14] R. Cheung, V. Ravyn, L. Wang, A. Ptasznik, and R. G. Collman, "Signaling mechanism of HIV-1 gp120 and virioninduced IL-1 $\beta$ release in primary human macrophages," Journal of Immunology, vol. 180, no. 10, pp. 6675-6684, 2008.

[15] B. M. Henrick, X. D. Yao, K. L. Rosenthal, and the INFANT study team, "HIV-1 structural proteins serve as PAMPs for TLR2 heterodimers significantly increasing infection and innate immune activation," Frontiers in Immunology, vol. 6, p. 426, 2015.

[16] M. Younas, C. Psomas, J. Reynes, and P. Corbeau, "Immune activation in the course of HIV-1 infection: causes, phenotypes and persistence under therapy," HIV Medicine, vol. 17, no. 2, pp. 89-105, 2016.

[17] M. G. Katusiime, G. U. Van Zyl, M. F. Cotton, and M. F. Kearney, "HIV-1 persistence in children during suppressive ART," Viruses, vol. 13, no. 6, p. 1134, 2021.

[18] T. Lyu, Y. Yue, E. Hsieh et al., "HIV-1 CRF01_AE subtype and HIV-1 DNA level among patients with chronic HIV-1 infection: a correlation study," BMC Infectious Diseases, vol. 20, no. 1, p. 66, 2020.

[19] S. D. Ismail, C. Riou, S. B. Joseph et al., "Immunological correlates of the HIV-1 replication-competent reservoir size," Clinical Infectious Diseases, 2021.

[20] K. Wu, S. Zhang, X. Zhang et al., "IL-21 expands HIV-1specific $\mathrm{CD}^{+} \mathrm{T}$ memory stem cells to suppress HIV-1 replication in vitro," Journal of Immunology Research, vol. 2019, Article ID 1801560, 13 pages, 2019.

[21] A. Vallejo, C. Gutierrez, B. Hernandez-Novoa et al., "The effect of intensification with raltegravir on the HIV-1 reservoir of latently infected memory CD4 T cells in suppressed patients," AIDS, vol. 26, no. 15, pp. 1885-1894, 2012.

[22] J. M. Llibre, M. J. Buzon, M. Massanella et al., "Treatment intensification with raltegravir in subjects with sustained HIV-1 viraemia suppression: a randomized 48-week study," Antiviral Therapy, vol. 17, no. 2, pp. 355-364, 2011.

[23] P. Nowak, M. Troseid, E. Avershina et al., "Gut microbiota diversity predicts immune status in HIV-1 infection," AIDS, vol. 29, no. 18, pp. 2409-2418, 2015.

[24] B. W. Wolf, K. B. Wheeler, D. G. Ataya, and K. A. Garleb, "Safety and tolerance of Lactobacillus reuteri supplementation to a population infected with the human immunodeficiency virus," Food and Chemical Toxicology, vol. 36, no. 12, pp. 1085-1094, 1998.

[25] A. S. Zevin, L. McKinnon, A. Burgener, and N. R. Klatt, "Microbial translocation and microbiome dysbiosis in HIVassociated immune activation," Current Opinion in HIV and AIDS, vol. 11, no. 2, pp. 182-190, 2016.

[26] J. M. Brenchley, T. W. Schacker, L. E. Ruff et al., "CD4+ T cell depletion during all stages of HIV disease occurs predominantly in the gastrointestinal tract," The Journal of Experimental Medicine, vol. 200, no. 6, pp. 749-759, 2004.
[27] L. Huang, J. Deng, R. Lang, G. Liao, and W. Jiang, "Enriched LPS staining within the germinal center of a lymph node from an HIV-infected long-term nonprogressor but not from progressors," Journal of Immunology Research, vol. 2020, Article ID 7471380, 5 pages, 2020.

[28] G. Marchetti, G. M. Bellistrì, E. Borghi et al., "Microbial translocation is associated with sustained failure in $\mathrm{CD} 4+$ T-cell reconstitution in HIV-infected patients on long-term highly active antiretroviral therapy," AIDS, vol. 22, no. 15 , pp. 2035-2038, 2008.

[29] G. Marchetti, C. Tincati, and G. Silvestri, "Microbial translocation in the pathogenesis of HIV infection and AIDS," Clinical Microbiology Reviews, vol. 26, no. 1, pp. 2-18, 2013.

[30] D. M. Dinh, G. E. Volpe, C. Duffalo et al., "Intestinal microbiota, microbial translocation, and systemic inflammation in chronic HIV infection," The Journal of Infectious Diseases, vol. 211, no. 1, pp. 19-27, 2015.

[31] J. Nilsson, A. Boasso, P. A. Velilla et al., "HIV-1-driven regulatory T-cell accumulation in lymphoid tissues is associated with disease progression in HIV/AIDS," Blood, vol. 108, no. 12, pp. 3808-3817, 2006.

[32] H. J. Epple, C. Loddenkemper, D. Kunkel et al., "Mucosal but not peripheral FOXP3+ regulatory $\mathrm{T}$ cells are highly increased in untreated HIV infection and normalize after suppressive HAART," Blood, vol. 108, no. 9, pp. 3072-3078, 2006.

[33] J. Andersson, A. Boasso, J. Nilsson et al., "Cutting edge: the prevalence of regulatory $\mathrm{T}$ cells in lymphoid tissue is correlated with viral load in HIV-infected patients," Journal of Immunology, vol. 174, no. 6, pp. 3143-3147, 2005.

[34] M. E. Moreno-Fernandez, W. Zapata, J. T. Blackard, G. Franchini, and C. A. Chougnet, "Human regulatory T cells are targets for human immunodeficiency virus (HIV) infection, and their susceptibility differs depending on the HIV type 1 strain," Journal of Virology, vol. 83, no. 24, pp. 12925-12933, 2009.

[35] T. Bopp, C. Becker, M. Klein et al., "Cyclic adenosine monophosphate is a key component of regulatory T cell-mediated suppression," The Journal of Experimental Medicine, vol. 204, no. 6, pp. 1303-1310, 2007.

[36] V. Terzieva, D. Popova, M. Kicheva et al., "Correlation between the degree of immune activation, production of IL2 and FOXP3 expression in CD4+CD25+ T regulatory cells in HIV-1 infected persons under HAART," International Immunopharmacology, vol. 9, no. 7-8, pp. 831-836, 2009.

[37] P. W. Hunt, A. L. Landay, E. Sinclair et al., "A low T regulatory cell response may contribute to both viral control and generalized immune activation in HIV controllers," PLoS One, vol. 6, no. 1, article e15924, 2011.

[38] J. M. Shaw, P. W. Hunt, J. W. Critchfield et al., "Short communication: HIV+ viremic slow progressors maintain low regulatory $\mathrm{T}$ cell numbers in rectal mucosa but exhibit high T cell activation," AIDS Research and Human Retroviruses, vol. 29, no. 1, pp. 172-177, 2013.

[39] A. L. Rodriguez-Perea, C. J. Montoya, S. Olek, C. A. Chougnet, and P. A. Velilla, "Statins increase the frequency of circulating $\mathrm{CD}^{+} \mathrm{FOXP}^{+}$regulatory $\mathrm{T}$ cells in healthy individuals," Journal of Immunology Research, vol. 2015, Article ID 762506, 8 pages, 2015.

[40] M. L. Freeman, J. C. Mudd, C. L. Shive et al., "CD8 T-cell expansion and inflammation linked to CMV coinfection in 
ART-treated HIV infection," Clinical Infectious Diseases, vol. 62 , no. 3, pp. 392-396, 2016.

[41] A. Boulougoura and I. Sereti, "HIV infection and immune activation," Current Opinion in HIV and AIDS, vol. 11, no. 2, pp. 191-200, 2016.

[42] Z. A. Sullivan, E. B. Wong, T. Ndung'u, V. O. Kasprowicz, and W. R. Bishai, "Latent and active tuberculosis infection increase immune activation in individuals co-infected with HIV," eBioMedicine, vol. 2, no. 4, pp. 334-340, 2015.

[43] P. W. Hunt, J. N. Martin, E. Sinclair et al., "Valganciclovir reduces $\mathrm{T}$ cell activation in $\mathrm{HIV}$-infected individuals with incomplete $\mathrm{CD} 4^{+} \mathrm{T}$ cell recovery on antiretroviral therapy," The Journal of Infectious Diseases, vol. 203, no. 10, pp. 1474-1483, 2011.

[44] J. B. Margolick, J. H. Bream, T. L. Nilles et al., "Relationship between T-cell responses to CMV, markers of inflammation, and frailty in HIV-uninfected and HIV-infected men in the multicenter AIDS cohort study," The Journal of Infectious Diseases, vol. 218, no. 2, pp. 249-258, 2018.

[45] K. J. Looker, J. A. R. Elmes, S. L. Gottlieb et al., "Effect of HSV-2 infection on subsequent HIV acquisition: an updated systematic review and meta-analysis," The Lancet Infectious Diseases, vol. 17, no. 12, pp. 1303-1316, 2017.

[46] P. van de Perre, M. Segondy, V. Foulongne et al., "Herpes simplex virus and HIV-1: deciphering viral synergy," The Lancet Infectious Diseases, vol. 8, no. 8, pp. 490-497, 2008.

[47] P. A. Rubbo, E. Tuaillon, N. Nagot et al., "HIV-1 infection impairs HSV-specific $\mathrm{CD}^{+}$and $\mathrm{CD}^{+}$T-cell response by reducing Th1 cytokines and CCR5 ligand secretion," Journal of Acquired Immune Deficiency Syndromes, vol. 58, no. 1, pp. 9-17, 2011.

[48] A. R. Retamal-Diaz, A. M. Kalergis, S. M. Bueno, and P. A. Gonzalez, "A herpes simplex virus type 2 deleted for glycoprotein $\mathrm{D}$ enables dendritic cells to activate $\mathrm{CD} 4^{+}$and $\mathrm{CD}^{+}$T cells," Frontiers in Immunology, vol. 8, p. 904, 2017.

[49] J. A. Moreno, L. M. Beltran, A. Rubio-Navarro, J. Puig, J. M. Amaro-Villalobos, and J. Egido, "Influence of immune activation and inflammatory response on cardiovascular risk associated with the human immunodeficiency virus," Vascular Health and Risk Management, vol. 11, pp. 35-48, 2015.

[50] M. Huang, J. D. Jiang, and Z. Peng, "Recent advances in the anti-HCV mechanisms of interferon," Acta Pharmaceutica Sinica B, vol. 4, no. 4, pp. 241-247, 2014.

[51] H. Li, M. H. Huang, J. D. Jiang, and Z. G. Peng, "Hepatitis C: from inflammatory pathogenesis to anti-inflammatory/hepatoprotective therapy," World Journal of Gastroenterology, vol. 24, no. 47, pp. 5297-5311, 2018.

[52] J. J. Chang, A. Lacas, R. J. Lindsay et al., "Differential regulation of toll-like receptor pathways in acute and chronic HIV1 infection," AIDS, vol. 26, no. 5, pp. 533-541, 2012.

[53] K. Shuai and B. Liu, "Regulation of JAK-STAT signalling in the immune system," Nature Reviews Immunology, vol. 3, no. 11, pp. 900-911, 2003.

[54] C. M. Sanders, J. M. Cruse, and R. E. Lewis, "Toll-like receptors, cytokines and HIV-1," Experimental and Molecular Pathology, vol. 84, no. 1, pp. 31-36, 2008.

[55] D. M. Giraldo, J. C. Hernandez, and S. Urcuqui-Inchima, "HIV-1-derived single-stranded RNA acts as activator of human neutrophils," Immunologic Research, vol. 64, no. 56, pp. 1185-1194, 2016.
[56] A. Shah, A. S. Verma, K. H. Patel et al., "HIV-1 gp120 induces expression of IL-6 through a nuclear factor-kappa Bdependent mechanism: suppression by gp120 specific small interfering RNA," PLoS One, vol. 6, no. 6, article e21261, 2011.

[57] A. R. Nookala and A. Kumar, "Molecular mechanisms involved in HIV-1 Tat-mediated induction of IL-6 and IL-8 in astrocytes," Journal of Neuroinflammation, vol. 11, no. 1, p. 214, 2014.

[58] G. S. Youn, D. J. Kwon, S. M. Ju et al., "Celastrol ameliorates HIV-1 Tat-induced inflammatory responses via NF-kappaB and AP-1 inhibition and heme oxygenase- 1 induction in astrocytes," Toxicology and Applied Pharmacology, vol. 280, no. 1, pp. 42-52, 2014.

[59] X. Ye, Y. Zhang, Q. Xu et al., "HIV-1 Tat inhibits EAAT-2 through AEG-1 upregulation in models of HIV-associated neurocognitive disorder," Oncotarget, vol. 8, no. 24, pp. 39922-39934, 2017.

[60] B. He, J. T. Tran, and D. J. Sanchez, "Manipulation of type I interferon signaling by HIV and AIDS-associated viruses," Journal of Immunology Research, vol. 2019, Article ID 8685312, 10 pages, 2019.

[61] F. Wan and M. J. Lenardo, "The nuclear signaling of NF- $\kappa$ B: current knowledge, new insights, and future perspectives," Cell Research, vol. 20, no. 1, pp. 24-33, 2010.

[62] P. M. Pitha, "Innate antiviral response: role in HIV-1 infection," Viruses, vol. 3, no. 7, pp. 1179-1203, 2011.

[63] A. Okumura, G. Lu, I. Pitha-Rowe, and P. M. Pitha, "Innate antiviral response targets HIV-1 release by the induction of ubiquitin-like protein ISG15," Proceedings of the National Academy of Sciences of the United States of America, vol. 103, no. 5, pp. 1440-1445, 2006.

[64] C. Scagnolari, K. Monteleone, C. Selvaggi et al., "ISG15 expression correlates with HIV-1 viral load and with factors regulating T cell response," Immunobiology, vol. 221, no. 2, pp. 282-290, 2016.

[65] S. Darb-Esfahani, B. V. Sinn, M. Rudl et al., "Interferon-stimulated gene, $15 \mathrm{kDa}$ (ISG15) in ovarian high-grade serous carcinoma," International Journal of Gynecological Pathology, vol. 33, no. 1, pp. 16-22, 2014.

[66] X. Wu, L. L. Zhang, L. B. Yin et al., "Deregulated microRNA21 expression in monocytes from HIV-infected patients contributes to elevated IP-10 secretion in HIV infection," Frontiers in Immunology, vol. 8, p. 1122, 2017.

[67] E. A. Miao, J. V. Rajan, and A. Aderem, "Caspase-1-induced pyroptotic cell death," Immunological Reviews, vol. 243, no. 1, pp. 206-214, 2011.

[68] Z. Q. Yao, D. Cao, S. Khanal et al., "A matter of life or death: productively infected and bystander CD4 T cells in early HIV infection," Frontiers in Immunology, vol. 11, article 626431, 2020.

[69] W. H. V. Carvalho-Silva, J. L. Andrade-Santos, F. O. Souto, A. V. C. Coelho, S. Crovella, and R. L. Guimaraes, "Immunological recovery failure in cART-treated HIV-positive patients is associated with reduced thymic output and RTE CD4+ T cell death by pyroptosis," Journal of Leukocyte Biology, vol. 107, no. 1, pp. 85-94, 2020.

[70] G. Doitsh, N. L. Galloway, X. Geng et al., "Cell death by pyroptosis drives CD4 T-cell depletion in HIV-1 infection," Nature, vol. 505, no. 7484, pp. 509-514, 2014.

[71] R. Cai, L. Liu, B. Luo et al., "Caspase-1 activity in CD4 T cells is downregulated following antiretroviral therapy for HIV-1 
infection," AIDS Research and Human Retroviruses, vol. 33, no. 2, pp. 164-171, 2017.

[72] R. P. J. Lai, G. Meintjes, K. A. Wilkinson et al., "HIV-tuberculosis-associated immune reconstitution inflammatory syndrome is characterized by toll-like receptor and inflammasome signalling," Nature Communications, vol. 6, no. 1, p. 8451, 2015.

[73] N. Van Opdenbosch and M. Lamkanfi, "Caspases in cell death, inflammation, and disease," Immunity, vol. 50, no. 6, pp. 1352-1364, 2019.

[74] T. P. Hurst, A. Aswad, T. Karamitros, A. Katzourakis, A. L. Smith, and G. Magiorkinis, "Interferon-inducible protein 16 (IFI16) has a broad-spectrum binding ability against ssDNA targets: an evolutionary hypothesis for antiretroviral checkpoint," Frontiers in Microbiology, vol. 10, p. 1426, 2019.

[75] N. L. Galloway, G. Doitsh, K. M. Monroe et al., "Cell-to-cell transmission of HIV-1 is required to trigger pyroptotic death of lymphoid-tissue-derived CD4 T cells," Cell Reports, vol. 12, no. 10, pp. 1555-1563, 2015.

[76] C. Kasang, A. Ulmer, N. Donhauser et al., "HIV patients treated with low-dose prednisolone exhibit lower immune activation than untreated patients," BMC Infectious Diseases, vol. 12, no. 1, p. 14, 2012.

[77] R. S. Wallis, R. Kalayjian, J. M. Jacobson et al., "A study of the immunology, virology, and safety of prednisone in HIV-1infected subjects with CD4 cell counts of 200 to $700 \mathrm{~mm}$ -3," Journal of Acquired Immune Deficiency Syndromes, vol. 32, no. 3, pp. 281-286, 2003.

[78] C. Kasang, S. Kalluvya, C. Majinge et al., "Effects of prednisolone on disease progression in antiretroviral-untreated HIV infection: a 2-year randomized, double-blind placebocontrolled clinical trial," PLoS One, vol. 11, no. 1, article e0146678, 2016.

[79] A. Ulmer, M. Muller, B. Bertisch-Mollenhoff, and B. Frietsch, "Low dose prednisolone reduces CD4+ T cell loss in therapynaive HIV-patients without antiretroviral therapy," European Journal of Medical Research, vol. 10, no. 3, pp. 105-109, 2005.

[80] J. M. Andrieu, W. Lu, and R. Levy, "Sustained increases in CD4 cell counts in asymptomatic human," The Journal of Infectious Diseases, vol. 171, no. 3, pp. 523-530, 1995.

[81] C. Argyropoulos and A. Mouzaki, "Immunosuppressive drugs in HIV disease," Current Topics in Medicinal Chemistry, vol. 6, no. 16, pp. 1769-1789, 2006.

[82] K. Sperber, T. H. Kalb, V. J. Stecher, R. Banerjee, and L. Mayer, "Inhibition of human immunodeficiency virus type 1 replication by hydroxychloroquine in T cells and monocytes," AIDS Research and Human Retroviruses, vol. 9, no. 1, pp. 91-98, 1993.

[83] S. M. Murray, C. M. Down, D. R. Boulware et al., "Reduction of immune activation with chloroquine therapy during chronic HIV infection," Journal of Virology, vol. 84, no. 22, pp. 12082-12086, 2010.

[84] S. Piconi, S. Parisotto, G. Rizzardini et al., "Hydroxychloroquine drastically reduces immune activation in HIV-infected, antiretroviral therapy-treated immunologic nonresponders," Blood, vol. 118, no. 12, pp. 3263-3272, 2011.

[85] N. I. Paton, R. L. Goodall, D. T. Dunn et al., "Effects of hydroxychloroquine on immune activation and disease progression among HIV-infected patients not receiving antiretroviral Therapy," JAMA, vol. 308, no. 4, pp. 353-361, 2012.
[86] J. P. Routy, J. B. Angel, M. Patel et al., “Assessment of chloroquine as a modulator of immune activation to improve CD4 recovery in immune nonresponding HIV-infected patients receiving antiretroviral therapy," HIV Medicine, vol. 16, no. 1, pp. 48-56, 2015.

[87] R. Levy, J. P. Jais, J. M. Tourani, P. Even, and J. M. Andrieu, "Long-term follow-up of HIV positive asymptomatic patients having received cyclosporin A," Advances in Experimental Medicine and Biology, vol. 374, pp. 229-234, 1995.

[88] T. Diaz, S. Y. Chu, J. W. Buehler et al., "Socioeconomic differences among people with AIDS: results from a multistate surveillance project," American Journal of Preventive Medicine, vol. 10, no. 4, pp. 217-222, 1994.

[89] J. M. Andrieu, P. Even, A. Venet et al., "Effects of cyclosporin on T-cell subsets in human immunodeficiency virus disease," Clinical Immunology and Immunopathology, vol. 47, no. 2, pp. 181-198, 1988.

[90] A. R. Martin, R. A. Pollack, A. Capoferri, R. F. Ambinder, C. M. Durand, and R. F. Siliciano, "Rapamycin-mediated mTOR inhibition uncouples HIV-1 latency reversal from cytokine-associated toxicity," The Journal of Clinical Investigation, vol. 127, no. 2, pp. 651-656, 2017.

[91] G. P. Rizzardi, A. Harari, B. Capiluppi et al., "Treatment of primary HIV-1 infection with cyclosporin A coupled with highly active antiretroviral therapy," The Journal of Clinical Investigation, vol. 109, no. 5, pp. 681-688, 2002.

[92] L. H. Calabrese, M. M. Lederman, J. Spritzler et al., "Placebocontrolled trial of cyclosporin-A in HIV-1 disease: implications for solid organ transplantation," Journal of Acquired Immune Deficiency Syndromes, vol. 29, no. 4, pp. 356-362, 2002.

[93] A. Phillips, M. A. Wainberg, R. Coates et al., "Cyclosporineinduced deterioration in patients with AIDS," CMAJ, vol. 140, no. 12, pp. 1456-1460, 1989.

[94] A. Heredia, A. Amoroso, C. Davis et al., "Rapamycin causes down-regulation of CCR 5 and accumulation of anti-HIV $\beta$ chemokines: an approach to suppress R5 strains of HIV-1," Proceedings of the National Academy of Sciences of the United States of America, vol. 100, no. 18, pp. 1041110416, 2003.

[95] J. Gonzalez, T. Harris, G. Childs, and M. B. Prystowsky, "Rapamycin blocks IL-2-driven T cell cycle progression while preserving T cell survival," Blood Cells, Molecules \& Diseases, vol. 27, no. 3, pp. 572-585, 2001.

[96] J. Roy, J. S. Paquette, J. F. Fortin, and M. J. Tremblay, "The immunosuppressant rapamycin represses human immunodeficiency virus type 1 replication," Antimicrobial Agents and Chemotherapy, vol. 46, no. 11, pp. 3447-3455, 2002.

[97] F. di Benedetto, S. di Sandro, N. de Ruvo et al., "First report on a series of HIV patients undergoing rapamycin monotherapy after liver transplantation," Transplantation, vol. 89, no. 6, pp. 733-738, 2010.

[98] R. Goldbach-Mansky, M. Wilson, R. Fleischmann et al., "Comparison of Tripterygium wilfordii Hook F versus sulfasalazine in the treatment of rheumatoid arthritis," Annals of Internal Medicine, vol. 151, no. 4, p. 229, 2009.

[99] J. Ren, Q. Tao, X. Wang, Z. Wang, and J. Li, "Efficacy of T2 in active Crohn's disease: a prospective study report," Digestive Diseases and Sciences, vol. 52, no. 8, pp. 1790-1797, 2007.

[100] Y. Lu, X. Bao, T. Sun, J. Xu, W. Zheng, and P. Shen, “Triptolide attenuate the oxidative stress induced by LPS/D-GalN in 
mice," Journal of Cellular Biochemistry, vol. 113, no. 3, pp. 1022-1033, 2012.

[101] V. Premkumar, M. Dey, R. Dorn, and I. Raskin, "MyD88dependent and independent pathways of toll-like receptors are engaged in biological activity of triptolide in ligandstimulated macrophages," BMC Chemical Biology, vol. 10, no. 1, p. 3, 2010.

[102] R. Matta, X. Wang, H. Ge, W. Ray, L. D. Nelin, and Y. Liu, "Triptolide induces anti-inflammatory cellular responses," American Journal of Translational Research, vol. 1, no. 3, pp. 267-282, 2009.

[103] J. Ma, M. Dey, H. Yang et al., "Anti-inflammatory and immunosuppressive compounds from _Tripterygium wilfordii_," Phytochemistry, vol. 68, no. 8, pp. 1172-1178, 2007.

[104] T. Li, J. Xie, Y. Li et al., "Tripterygium wilfordii Hook F extract in cART-treated HIV patients with poor immune response: a pilot study to assess its immunomodulatory effects and safety," HIV Clinical Trials, vol. 16, no. 2, pp. 49-56, 2015.

[105] A. Ganesan, N. Crum-Cianflone, J. Higgins et al., "High dose atorvastatin decreases cellular markers of immune activation without affecting HIV-1 RNA levels: results of a double-blind randomized placebo controlled clinical trial," The Journal of Infectious Diseases, vol. 203, no. 6, pp. 756-764, 2011.

[106] A. R. Eckard, Y. Jiang, S. M. Debanne, N. T. Funderburg, and G. A. McComsey, "Effect of 24 weeks of statin therapy on systemic and vascular inflammation in HIV-infected subjects receiving antiretroviral therapy," The Journal of Infectious Diseases, vol. 209, no. 8, pp. 1156-1164, 2014.

[107] N. T. Funderburg, Y. Jiang, S. M. Debanne et al., "Rosuvastatin reduces vascular inflammation and T-cell and monocyte activation in HIV-infected subjects on antiretroviral therapy," Journal of Acquired Immune Deficiency Syndromes, vol. 68, no. 4, pp. 396-404, 2015.

[108] M. J. Feinstein, C. J. Achenbach, N. J. Stone, and D. M. LloydJones, "A systematic review of the usefulness of statin therapy in HIV-infected patients," The American Journal of Cardiology, vol. 115, no. 12, pp. 1760-1766, 2015.

[109] G. d'Ettorre, G. Ceccarelli, N. Giustini et al., "Probiotics reduce inflammation in antiretroviral treated, HIV-infected individuals: results of the "Probio-HIV" clinical trial," PLoS One, vol. 10, no. 9, article e0137200, 2015.

[110] R. Hummelen, J. Changalucha, N. L. Butamanya et al., "Effect of 25 weeks probiotic supplementation on immune function of HIV patients," Gut Microbes, vol. 2, no. 2, pp. 80-85, 2011.

[111] N. R. Klatt, L. A. Canary, X. Sun et al., "Probiotic/prebiotic supplementation of antiretrovirals improves gastrointestinal immunity in SIV-infected macaques," The Journal of Clinical Investigation, vol. 123, no. 2, pp. 903-907, 2013.

[112] M. Schunter, H. Chu, T. L. Hayes et al., "Randomized pilot trial of a synbiotic dietary supplement in chronic HIV-1 infection," BMC Complementary and Alternative Medicine, vol. 12, no. 1, p. 84, 2012.

[113] L. A. González-Hernández, L. F. Jave-Suarez, M. FafutisMorris et al., "Synbiotic therapy decreases microbial translocation and inflammation and improves immunological status in HIV-infected patients: a double-blind randomized controlled pilot trial," Nutrition Journal, vol. 11, no. 1, p. 90, 2012.

[114] J. Villar-García, J. J. Hernández, R. Güerri-Fernández et al., "Effect of probiotics (Saccharomyces boulardii) on microbial translocation and inflammation in HIV-treated Patients,"
Journal of Acquired Immune Deficiency Syndromes, vol. 68, no. 3, pp. 256-263, 2015.

[115] B. Lebouché, M. A. Jenabian, J. Singer et al., "The role of extended-release niacin on immune activation and neurocognition in HIV-infected patients treated with antiretroviral therapy - CTN PT006: study protocol for a randomized controlled trial," Trials, vol. 15, no. 1, p. 390, 2014.

[116] O. Sortino, K. H. Hullsiek, E. Richards et al., "The effects of recombinant human lactoferrin on immune activation and the intestinal microbiome among persons living with human immunodeficiency virus and receiving antiretroviral therapy," The Journal of Infectious Diseases, vol. 219, no. 12, pp. 1963-1968, 2019.

[117] C. Stradling, G. N. Thomas, K. Hemming, S. Taylor, and S. Taheri, "Randomized parallel-group pilot trial (Best foods for your heart) comparing the effects of a Mediterranean Portfolio diet with a low saturated fat diet on HIV dyslipidemia," Clinical Nutrition, vol. 40, no. 3, pp. 860-869, 2021.

[118] K. Fitch, S. Abbara, H. Lee et al., "Effects of lifestyle modification and metformin on atherosclerotic indices among HIVinfected patients with the metabolic syndrome," AIDS, vol. 26, no. 5, pp. 587-597, 2012.

[119] C. M. Shikuma, G. M. Chew, L. Kohorn et al., "Short communication: metformin reduces CD4 T cell exhaustion in HIVinfected adults on suppressive antiretroviral therapy," AIDS Research and Human Retroviruses, vol. 36, no. 4, pp. 303305, 2020.

[120] D. Planas, A. Pagliuzza, R. Ponte et al., "LILAC pilot study: effects of metformin on mTOR activation and HIV reservoir persistence during antiretroviral therapy," eBioMedicine, vol. 65, article 103270, 2021.

[121] J. P. Routy, S. Isnard, V. Mehraj et al., "Effect of metformin on the size of the HIV reservoir in non-diabetic ART-treated individuals: single-arm non-randomised Lilac pilot study protocol," BMJ Open, vol. 9, no. 4, article e028444, 2019.

[122] C. Best, H. Struthers, E. Laciny, M. Royal, D. N. Reeds, and K. E. Yarasheski, "Sitagliptin reduces inflammation and chronic immune cell activation in HIV+ adults with impaired glucose tolerance," The Journal of Clinical Endocrinology and Metabolism, vol. 100, no. 7, pp. 2621-2629, 2015.

[123] M. O’Brien, E. Montenont, L. Hu et al., “Aspirin attenuates platelet activation and immune activation in HIV-1-infected subjects on antiretroviral therapy," Journal of Acquired Immune Deficiency Syndromes, vol. 63, no. 3, pp. 280-288, 2013.

[124] M. P. O’Brien, M. U. Zafar, J. C. Rodriguez et al., “Targeting thrombogenicity and inflammation in chronic HIV infection," Science Advances, vol. 5, no. 6, 2019.

[125] F. O. Pettersen, E. A. Torheim, A. E. Dahm et al., “An exploratory trial of cyclooxygenase type 2 inhibitor in HIV-1 infection: downregulated immune activation and improved T celldependent vaccine responses," Journal of Virology, vol. 85, no. 13, pp. 6557-6566, 2011.

[126] C. Prebensen, M. Trøseid, T. Ueland et al., "Immune activation and HIV-specific $\mathrm{T}$ cell responses are modulated by a cyclooxygenase-2 inhibitor in untreated HIV-infected individuals: an exploratory clinical trial," PLoS One, vol. 12, no. 5, article e0176527, 2017.

[127] E. E. Lutge, A. Gray, N. Siegfried, and Cochrane HIV/AIDS Group, "The medical use of cannabis for reducing morbidity and mortality in patients with HIV/AIDS," Cochrane Database of Systematic Reviews, no. 4, article CD005175, 2013. 
[128] F. Grotenhermen and K. Muller-Vahl, "The therapeutic potential of cannabis and cannabinoids," Deutsches Ärzteblatt International, vol. 109, no. 29-30, pp. 495-501, 2012.

[129] J. A. Manuzak, T. M. Gott, J. S. Kirkwood et al., "Heavy Cannabis use associated with reduction in activated and inflammatory immune cell frequencies in antiretroviral therapytreated human immunodeficiency virus-infected individuals," Clinical Infectious Diseases, vol. 66, no. 12, pp. 18721882, 2018.

[130] R. J. Ellis, S. N. Peterson, Y. Li et al., "Recent cannabis use in $\mathrm{HIV}$ is associated with reduced inflammatory markers in CSF and blood," Neurol Neuroimmunol Neuroinflamm, vol. 7, no. $5,2020$.

[131] S. I. Valdes-Ferrer, J. C. Crispin, P. F. Belaunzaran, C. G. Cantu-Brito, J. Sierra-Madero, and J. Alcocer-Varela, "Acetylcholine-esterase inhibitor pyridostigmine decreases $\mathrm{T}$ cell overactivation in patients infected by HIV," AIDS Research and Human Retroviruses, vol. 25, no. 8, pp. 749-755, 2009.

[132] K. A. Metcalf Pate and J. L. Mankowski, "HIV and SIV associated thrombocytopenia: an expanding role for platelets in the pathogenesis of HIV," Drug Discovery Today: Disease Mechanisms, vol. 8, no. 1-2, pp. e25-e32, 2011.

[133] B. J. C. Macatangay, E. K. Jackson, K. Z. Abebe et al., “A randomized, placebo-controlled, pilot clinical trial of dipyridamole to decrease human immunodeficiency virus-associated chronic inflammation," The Journal of Infectious Diseases, vol. 221, no. 10, pp. 1598-1606, 2020.

[134] M. Somsouk, R. M. Dunham, M. Cohen et al., “The immunologic effects of mesalamine in treated HIV-infected individuals with incomplete $\mathrm{CD} 4+\mathrm{T}$ cell recovery: a randomized crossover trial," PLoS One, vol. 9, no. 12, article e116306, 2014.

[135] H. M. Cherwinski, R. G. Cohn, P. Cheung et al., "The immunosuppressant leflunomide inhibits lymphocyte proliferation by inhibiting pyrimidine biosynthesis," The Journal of Pharmacology and Experimental Therapeutics, vol. 275, no. 2, pp. 1043-1049, 1995.

[136] S. W. Read, M. DeGrezia, E. J. Ciccone et al., "The effect of leflunomide on cycling and activation of T-cells in HIV-1infected participants," PLoS One, vol. 5, no. 8, article e11937, 2010.

[137] P. Y. Hsue, H. J. Ribaudo, S. G. Deeks et al., "Safety and impact of low-dose methotrexate on endothelial function and inflammation in individuals with treated human immunodeficiency virus: AIDS Clinical Trials Group study A5314," Clinical Infectious Diseases, vol. 68, no. 11, pp. 1877-1886, 2019. 